\title{
Instrumented fusion for spinal deformity after laminectomy or laminoplasty for resection of intramedullary spinal cord tumors in pediatric patients
}

\author{
David S. Hersh, MD, ${ }^{1}$ Rajiv R. lyer, MD, ${ }^{2}$ Tomas Garzon-Muvdi, MD, MSc, ${ }^{2}$ Ann Liu, MD, ${ }^{2}$ \\ George I. Jallo, MD, ${ }^{2,3}$ and Mari L. Groves, MD1,2
}

\begin{abstract}
${ }^{1}$ Department of Neurosurgery, University of Maryland School of Medicine; 2Division of Pediatric Neurosurgery, Department of Neurosurgery, Johns Hopkins University School of Medicine, Baltimore, Maryland; and 3Institute for Brain Protection Sciences, Johns Hopkins All Children's Hospital, Saint Petersburg, Florida
\end{abstract}

\begin{abstract}
OBJECTIVE Spinal deformity has become a well-recognized complication of intramedullary spinal cord tumor (IMSCT) resection. In particular, laminectomy can result in biomechanical instability caused by loss of the posterior tension band. Therefore, laminoplasty has been proposed as an alternative to laminectomy. Here, the authors describe the largest current series of pediatric patients who have undergone laminoplasty for IMSCT resection and investigate the need for surgical fusion after both laminectomy and laminoplasty.

METHODS The medical records of pediatric patients who underwent resection of an IMSCT at a single institution between November 2003 and May 2014 were reviewed retrospectively. Demographic, clinical, radiological, surgical, histopathological, and follow-up data were collected.
\end{abstract}

RESULTS Sixty-six consecutive patients underwent resection of an IMSCT during the study period. Forty-three (65\%) patients were male. The patients had a median age of 12.9 years (interquartile range [IQR] 7.2-16.5 years) at the time of surgery. Patients typically presented with a tumor that involved the cervical and/or thoracic spine. Nineteen (29\%) patients underwent laminectomy, and $47(71 \%)$ patients underwent laminoplasty. Patients in each cohort had a similar rate of postoperative deformity. Overall, $10(15 \%)$ patients required instrumented spinal fusion for spinal deformity. Four patients required revision of the primary fusion.

CONCLUSIONS These findings show that among pediatric patients with an IMSCT, postoperative surgical fusion rates remain high, even after laminoplasty. Known risk factors, such as the age of the patient, location of the tumor, and the number of involved levels, might play a larger role than replacement of the laminae in determining the rate of surgical fusion after IMSCT resection.

https://thejns.org/doi/abs/10.3171/2017.7.FOCUS17329

KEY WORDS intramedullary; laminoplasty; deformity; kyphosis; scoliosis; fusion

$\mathrm{P}$ EDIATRIC intramedullary spinal cord tumors (IMSCTs) constitute 6\% of CNS tumors and $36 \%$ of pediatric intraspinal tumors. ${ }^{33}$ Advances in intraoperative neurophysiological monitoring and microsurgical techniques have facilitated more aggressive resection of IMSCTs, which has resulted in higher rates of long-term survival. ${ }^{7,14,15}$ However, with improved survival and longer follow-up times, postoperative spinal deformity has become a well-recognized complication of IMSCT resection.

Postoperative progressive spinal deformity has been reported in $16 \%-100 \%$ of pediatric patients after IMSCT re- section. ${ }^{3,8,11,16,26,30,34,37}$ A number of factors might contribute to the high rate of deformity in this unique patient population. Neurogenic spinal deformity can result from neuromuscular dysfunction and has been described similarly in other patient populations with paralysis, including those with spinal cord injury. ${ }^{17}$ Among patients with an IMSCT, anterior horn cell involvement by the tumor can cause musculoskeletal changes secondary to paravertebral muscle denervation and produce progressive deformity as a result of a lack of support and stabilization by the soft tissues that surround the vertebral column., ${ }^{2,31}$ Also, delayed-onset

ABBREVIATIONS IMSCT = intramedullary spinal cord tumor; $I Q R=$ interquartile range; $M E P=$ motor evoked potential.

SUBMITTED May 31, 2017. ACCEPTED July 10, 2017.

INCLUDE WHEN CITING DOI: 10.3171/2017.7.FOCUS17329. 
pediatric spinal deformity can occur after radiation therapy as a result of asymmetrical damage to the vertebral growth plates. ${ }^{5,8,9,20}$ Finally, loss of the posterior tension band after a laminectomy for IMSCT resection can produce biomechanical instability and result in an inability to maintain sagittal alignment, particularly in skeletally immature children. ${ }^{10}$ Progressive postlaminectomy kyphosis, therefore, is a potential complication in pediatric patients who have undergone multilevel laminectomy for IMSCT resection. ${ }^{6}$

Previous studies identified various predictors of postoperative spinal deformity after IMSCT surgery. Several strategies have been advocated for the prevention of progressive deformity in patients at high risk, including the prophylactic use of an external orthosis, early or concurrent fusion,, 32 and the use of laminoplasty as an alternative to laminectomy. ${ }^{22}$

Laminoplasty in particular has gained popularity in recent years. However, reported outcomes are limited to those in small cohorts ranging from 5 to 20 patients, typically included within a larger series in which the majority of the patients underwent laminectomy., ${ }^{2,22,37}$ As a result, the effect of laminoplasty on progressive postoperative deformity among pediatric patients who undergo IMSCT resection remains unclear. Here, we present the largest, to our knowledge, current series of pediatric patients undergoing laminoplasty for IMSCT resection and investigate the relationship between laminoplasty and postoperative spinal deformity in this unique patient population.

\section{Methods \\ Study Patients}

After approval by the Johns Hopkins University School of Medicine institutional review board, the medical records of 66 consecutive pediatric patients (aged 21 years or younger) who underwent resection of an IMSCT at a single institution between November 2003 and May 2014 were reviewed retrospectively. Demographic, clinical, radiological, surgical, histopathological, and follow-up data were collected. The location of each IMSCT was categorized as cervical, thoracic, lumbar, or sacral. Tumors that involved either C-7 or T-1 were categorized as cervicothoracic, those that involved either $\mathrm{T}-12$ or $\mathrm{L}-1$ were categorized as thoracolumbar, and those that involved either L-5 or S-1 were categorized as lumbosacral.

\section{Operative Management}

Each patient underwent surgery at the Johns Hopkins Children's Center in Baltimore, MD, and was treated by a pediatric neurosurgeon (G.I.J.). As previously described, ${ }^{23,35}$ each patient underwent laminectomy or laminoplasty that spanned the length of the lesion. For patients who were referred after having already undergone laminectomy at another institution, the tumor was accessed through the preexisting bony defect, which was expanded as needed. The remaining patients underwent laminoplasty unless decompression of the spinal cord was felt to be necessary based on the preoperative imaging. In every case, only the medial aspect of the facet was exposed, and care was taken to preserve the facet joint capsule. Facetec- tomy was not performed in any of the patients. Intraoperative neurophysiological monitoring included motor evoked potentials (MEPs) and somatosensory evoked potentials in all cases. Monitoring of D-waves (epidural MEPs) was also performed in all cases, except for patients in whom the tumor was in close proximity to the craniocervical junction or conus medullaris, which limits the surgeon's technical ability to place rostral and caudal leads. After accessing the tumor, bipolar electrocautery, suction, and ultrasonic aspiration were used to resect the tumor until the interface with the white matter was reached or until there was a sustained decrease in the MEPs of more than $50 \%$ of their baseline value.

\section{Postoperative Management}

After resection, the patients underwent clinical and radiological surveillance to monitor for tumor recurrence. In those with a histopathological diagnosis of a malignant tumor, and in cases of tumor recurrence, patients were also evaluated by a pediatric medical oncologist and pediatric radiation oncologist. Recommendations for chemotherapy and/or radiation therapy were discussed in a multidisciplinary manner. Patients with clinical and/or radiological evidence of deformity on surveillance MRI were evaluated by a pediatric orthopedic surgeon. All patients in whom deformity was suspected on clinical examination or surveillance MRI underwent standing anteroposterior and lateral scoliosis radiography. Cobb angles and the degree of kyphosis were measured in each patient. Additional standing scoliosis radiographs were obtained at intervals that depended on the age of the patient, the initial severity of the deformity, and the rate of progression. Interval imaging was obtained at least annually, or semiannually in patients for whom more rapid progression was a concern. Instrumented fusion was recommended for patients with progressive coronal or sagittal deformity despite nonsurgical management.

\section{Statistical Analysis}

Descriptive statistics were reported, including frequency and percentage for categorical variables and median and interquartile range (IQR) for continuous variables. The Fisher exact test was used to compare categorical variables between groups. The Mann-Whitney test was applied to compare continuous variables between the groups. A p value of $<0.05$ was considered statistically significant.

\section{Results}

\section{Patient Population}

A total of 66 consecutive patients underwent resection of a histopathologically confirmed IMSCT during the study period. Demographic, clinical, and surgical features are summarized in Table 1. Forty-three (65\%) patients were male, and 23 (35\%) patients were female, and their median age was 12.9 years (IQR 7.2-16.5 years) at the time of surgery. Patients presented most commonly with a tumor that involved the cervical and/or thoracic spine. The cervical spine was involved in $23(35 \%)$ patients, the thoracic spine in $21(32 \%)$ patients, and the cervicothoracic junction (C-7 
TABLE 1. Demographic, clinical, and surgical features

\begin{tabular}{|c|c|c|c|}
\hline Variable & $\begin{array}{l}\text { Laminectomy } \\
\qquad(\mathrm{n}=19)\end{array}$ & $\begin{array}{l}\text { Laminoplasty } \\
\qquad(\mathrm{n}=47)\end{array}$ & $\begin{array}{c}p \\
\text { Value }\end{array}$ \\
\hline Male (no. [\%]) & $12(63)$ & $31(66)$ & 1.00 \\
\hline Median age in yrs (IQR) & $13.0(10.8-15.9)$ & $12.3(5.3-17.3)$ & 0.23 \\
\hline Location (no. [\%]) & & & 0.24 \\
\hline Cervical & $8(42)$ & $15(32)$ & \\
\hline Cervicothoracic & $4(21)$ & $13(28)$ & \\
\hline Thoracic & $4(21)$ & $17(36)$ & \\
\hline Thoracolumbar & $1(5)$ & $2(4)$ & \\
\hline Lumbar & $0(0)$ & $0(0)$ & \\
\hline Lumbosacral & $1(5)$ & $0(0)$ & \\
\hline Sacral & $1(5)$ & $0(0)$ & \\
\hline \multicolumn{4}{|l|}{$\begin{array}{l}\text { Previous treatment (no. } \\
\text { [\%]) }\end{array}$} \\
\hline Biopsy or resection & $14(74)$ & $13(28)$ & $<0.001$ \\
\hline Chemotherapy & $7(37)$ & $3(6)$ & 0.004 \\
\hline Radiotherapy & $5(26)$ & $2(4)$ & 0.02 \\
\hline $\begin{array}{l}\text { Preoperative deformity } \\
(\text { no. }[\%])^{*}\end{array}$ & $2(33)$ & $6(26)$ & 1.00 \\
\hline $\begin{array}{l}\text { Median no. of levels } \\
\text { included in resection } \\
(\mathrm{IQR})\end{array}$ & $4(1.5-5)$ & $3(2-5)$ & 0.79 \\
\hline $\begin{array}{l}\text { Histopathological diagno- } \\
\text { sis (no. [\%]) }\end{array}$ & & & 0.42 \\
\hline Astrocytoma & $8(42)$ & $29(62)$ & \\
\hline Ependymoma & $5(26)$ & $6(13)$ & \\
\hline Ganglion-cell tumor† & $2(11)$ & $6(13)$ & \\
\hline Hemangioblastoma & $1(5)$ & $1(2)$ & \\
\hline Other & $3(16)$ & $5(11)$ & \\
\hline $\begin{array}{l}\text { Median length of stay in } \\
\text { days (IQR) }\end{array}$ & $6(4-7)$ & $5(4-6)$ & 0.39 \\
\hline Discharge (no. [\%]) & & & 0.76 \\
\hline Home & $13(68)$ & $34(72)$ & \\
\hline Rehabilitation facility & $6(32)$ & $13(28)$ & \\
\hline
\end{tabular}

and/or T-1) in 17 (26\%) patients. The thoracolumbar junction (T-12 and/or L-1) was involved in $3(5 \%)$ patients, and lumbar, sacral, and/or lumbosacral involvement was present in $2(3 \%)$ patients.

Many patients were referred for evaluation after having already undergone surgical or adjuvant therapy at another institution. Twenty-seven (41\%) patients underwent biopsy and/or resection(s) of the IMSCT before presenting to our institution. It is notable that $74 \%$ of the patients in the laminectomy cohort had undergone previous IMSCT surgery at another institution, in contrast to only $28 \%$ of the laminoplasty cohort $(\mathrm{p}<0.001)$. Patients who underwent laminectomy were also more likely to have been treated with chemotherapy ( $37 \%$ vs $6 \%$, respectively; $p=0.004)$ or radiation ( $26 \%$ vs $4 \%$, respectively; $\mathrm{p}=0.02)$ before presenting to our institution. Overall, $10(15 \%)$ patients had
TABLE 2. Postoperative management

\begin{tabular}{|c|c|c|c|}
\hline Variable & $\begin{array}{l}\text { Laminectomy } \\
\qquad(\mathrm{n}=19)\end{array}$ & $\begin{array}{l}\text { Laminoplasty } \\
\qquad(n=47)\end{array}$ & $\begin{array}{c}\mathrm{p} \\
\text { Value }\end{array}$ \\
\hline $\begin{array}{l}\text { Clinical and/or radiologi- } \\
\text { cal follow-up (no. [\%]) }\end{array}$ & $17(89)$ & $39(83)$ & 0.71 \\
\hline $\begin{array}{l}\text { Median follow-up length } \\
\text { in mos }(\mathrm{IQR})^{*}\end{array}$ & $25.3(9.7-58.8)$ & $22.8(2.5-65.6)$ & 0.98 \\
\hline \multicolumn{4}{|l|}{ Adjuvant therapy (no. [\%]) } \\
\hline Chemotherapy & $3(16)$ & $8(17)$ & 1.00 \\
\hline Radiotherapy & $4(21)$ & $4(9)$ & 0.21 \\
\hline $\begin{array}{l}\text { Biopsy and/or resection } \\
\text { (no. }[\%]) \dagger\end{array}$ & & & $<0.001$ \\
\hline 1 surgery & $4(21)$ & $31(66)$ & \\
\hline 2 surgeries & $6(32)$ & $11(23)$ & \\
\hline 3 surgeries & $7(37)$ & $5(11)$ & \\
\hline$\geq 4$ surgeries & $2(11)$ & $0(0)$ & \\
\hline $\begin{array}{l}\text { Postoperative deformity } \\
\text { (no. [\%]) }\end{array}$ & & & 0.81 \\
\hline Kyphosis & $12(63)$ & $28(60)$ & \\
\hline Scoliosis & $0(0)$ & $1(2)$ & \\
\hline Kyphoscoliosis & $3(16)$ & $10(21)$ & \\
\hline Total & $15(79)$ & $39(83)$ & \\
\hline $\begin{array}{l}\text { Instrumented fusion (no. } \\
{[\%] \text { ) }}\end{array}$ & $2(11)$ & $8(17)$ & 0.71 \\
\hline
\end{tabular}

* Patients who were lost to follow-up were excluded from this analysis. $\dagger$ Including any cases of biopsy and/or resection that were performed before presenting initially to Johns Hopkins Children's Hospital.

been treated with chemotherapy, which most commonly involved carboplatin and/or temozolomide. Seven (11\%) patients had been treated with radiation. In these cases, patients were referred for either persistence or recurrence of the IMSCT.

\section{Surgical Management of IMSCTs}

Nineteen (29\%) patients underwent laminectomy to access the IMSCT, and $47(71 \%)$ patients underwent laminoplasty. A median of 3 levels (IQR 2-5 levels) were included in the surgery. All IMSCT specimens were sent for histopathological analysis. The IMSCT was confirmed to be an astrocytoma in 37 (56\%) cases; in 7 (19\%) of these cases, the astrocytoma was high grade (anaplastic astrocytoma or glioblastoma), whereas in the remainder, the diagnosis was Grade I or II astrocytoma. In addition, ependymoma was the diagnosis in $11(17 \%)$ cases, ganglion-cell tumor (ganglioglioma or gangliocytoma) in $8(12 \%)$ cases, and hemangioblastoma in $2(3 \%)$ cases.

\section{Follow-Up}

After discharge to home (47 [71\%] patients) or a rehabilitation facility (19 [29\%] patients), the patients were followed up closely in the neurosurgical clinic and, when necessary, by a pediatric medical oncologist and pediatric radiation oncologist. Follow-up data and adjuvant treatments are summarized in Table 2. A total of $56(85 \%)$ patients had clinical and/or radiological follow-up, and 

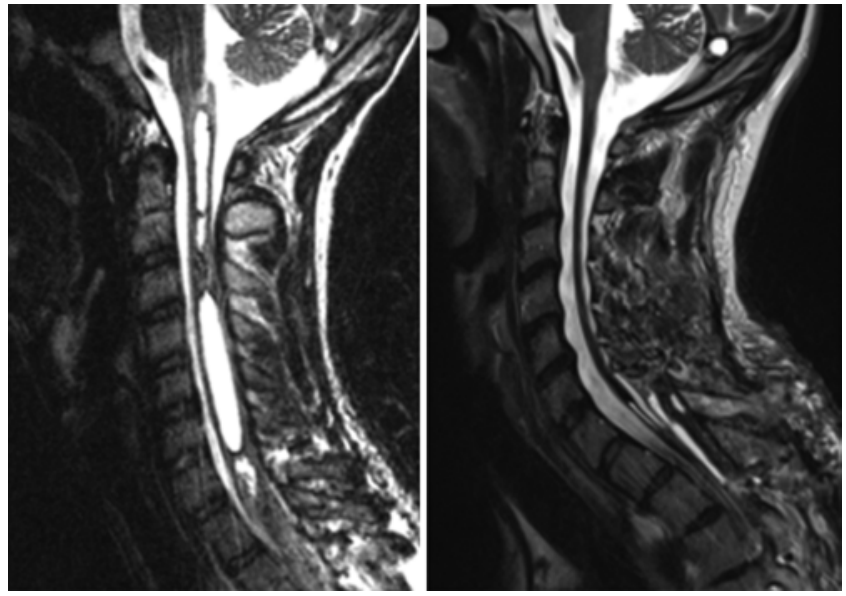

FIG. 1. A 16-year-old boy presented with an IMSCT that involved the cervicothoracic junction. Left: Preoperative T2-weighted sagittal MR image showing the IMSCT with proximal syringomyelia extending throughout the cervical spine. Right: Sagittal T2-weighted MR image obtained 12 years after laminoplasty for resection of the IMSCT showing a kyphotic deformity centered at the cervicothoracic junction.

the median follow-up duration was 24.1 months (IQR 2.5-64.8 months). Eleven (17\%) patients underwent adjuvant chemotherapy, and $8(12 \%)$ patients were treated with adjuvant radiation. Tumor recurrence was managed typically by re-resection, which was performed in nearly half the cohort. The median time to tumor recurrence was 16.0 months (IQR 7.6-30.5 months). Including, when applicable, tumor biopsy and/or resection that was performed before the initial presentation at our institution, 17 (26\%) patients underwent 2 IMSCT surgeries, 12 (18\%) underwent 3 surgeries, and $2(3 \%)$ underwent at least 4 surgeries. Patients in the laminoplasty cohort had fewer surgeries than those in the laminectomy cohort $(\mathrm{p}<$ 0.001 ). Two patients in the laminoplasty cohort underwent laminectomy during a subsequent surgery; the remainder of the patients underwent replacement of the laminae during each surgery.

\section{Spinal Deformity}

Patients underwent serial imaging after IMSCT resection. Forty $(61 \%)$ patients were noted to have a postoperative kyphotic deformity (Fig. 1), 1 patient had right thoracic scoliosis, and 13 (20\%) patients had kyphoscoliosis. Patients who underwent laminectomy and those who underwent laminoplasty had similar rates of postoperative deformity ( $79 \%$ vs $83 \%$, respectively).

Ten (15\%) patients underwent an instrumented fusion for spinal deformity (Fig. 2), accounting for $11 \%$ of the laminectomy cohort and $17 \%$ of the laminoplasty cohort $(p=0.71)$. The features of this subset of patients are summarized in Table 3. Of the 10 patients who underwent fusion, 1 patient required growing rods, 8 patients required posterior instrumentation, and 1 patient required anterior and posterior instrumentation. Instrumentation was performed at the discretion of our colleagues who specialize in pediatric spinal deformity. Posterior fusion consisted of pedicle screw instrumentation with the application of autograft and allograft. One patient had already had an in- strumented fusion before presenting to our institution. In addition, 1 patient had undergone a biopsy before undergoing concurrent resection and fusion; the remaining patients underwent fusion after having had 1 or more resections. The median interval between the patients' earliest biopsy/resection and fusion was 31.9 months (IQR 14.6-50.3 months). Two (20\%) of the 10 patients who required fusion had been treated with radiotherapy. One patient underwent a 28-day course of radiotherapy after biopsy at an outside institution and subsequently underwent resection of the IMSCT. The other patient underwent 2 IMSCT resections at an outside institution and then was treated with chemotherapy and radiotherapy before presenting to our institution. Two (20\%) patients had cervical involvement, $4(40 \%)$ patients had thoracic involvement, and $3(30 \%)$ patients had cervicothoracic involvement. Two (20\%) patients underwent laminectomy, and $8(80 \%)$ patients underwent laminoplasty. Overall, among the 31 patients who underwent 2 or more surgeries for biopsy and/or resection, $8(26 \%)$ ultimately underwent instrumented fusion. In contrast, only $2(6 \%)$ of the 34 patients who underwent a single resection later required fusion $(p=0.04)$. Four patients $(6 \%$ of the total cohort and $40 \%$ of those who underwent fusion) required a revision of the primary fusion as a result of adjacent segment disease, junctional kyphosis, and/or hardware failure.

\section{Discussion}

Progressive spinal deformity after IMSCT resection in pediatric patients has been well documented but with a highly variable reported incidence that has ranged from $16 \%$ to $100 \%{ }^{3,8,11,16,26,30,34,37}$ Although laminoplasty has been advocated as a means of reducing the rate of postoperative spinal deformity, reported outcomes after this technique have been limited to those in small case series, and its efficacy remains unclear. We present here a series of 66 consecutive pediatric patients who underwent IMSCT resection, 47 of whom underwent laminoplasty. To our knowledge, this represents the largest series to date of patients who underwent laminoplasty for IMSCT resection. We found that despite whether the tumor was accessed via laminectomy or laminoplasty, the patients experienced similar rates of postoperative deformity and similar rates of instrumented fusion. Other risk factors, therefore, might be more significant in determining the rate of surgical fusion after IMSCT resection.

Progressive deformity can contribute to pain and decreased quality of life in patients with long-term survival after IMSCT resection. Several studies were unable to identify an association between progressive spinal deformity and decreased functional outcomes. ${ }^{2,22}$ However, Yao et al.$^{35}$ found that although patients with and those without progressive spinal deformity had similar preoperative and 3-month postoperative functional scores, the patients with deformity had significantly worse functional outcomes at their last follow-up visit, even after surgical correction. Therefore, the ability to predict and prevent postoperative spinal deformity after IMSCT resection has attracted much interest.

Several forms of spinal deformity can coexist among 

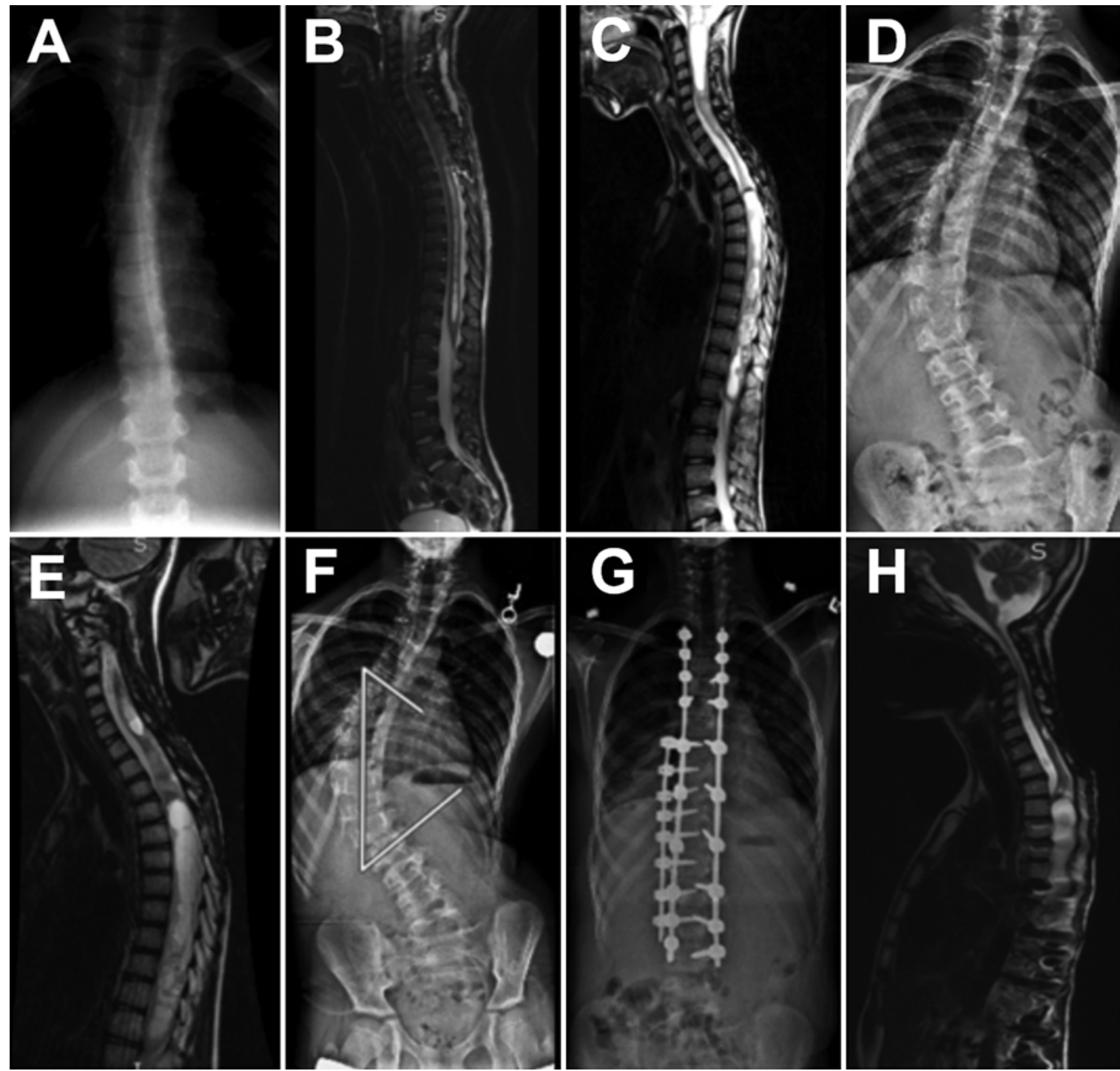

FIG. 2. A 7-year-old boy presented with an IMSCT spanning C5-T5. A: Preoperative chest radiograph showing mild dextroscoliosis. B: Sagittal T2-weighted MR image obtained immediately after cervical laminoplasty for IMSCT resection revealing global spinal alignment. C: Sagittal T2-weighted MR image obtained 3 years postoperatively demonstrating a cervical kyphotic deformity. D: Plain radiograph obtained 5 years postoperatively showing thoracolumbar dextroscoliosis with a Cobb angle of $48^{\circ}$. E: Sagittal T2-weighted MR image obtained 5 years after the initial resection revealing continued progression. F: Plain radiograph obtained 6 years postoperatively showing scoliotic progression with a Cobb angle of $76^{\circ}$. G: Plain radiograph obtained after thoracolumbar fusion demonstrating correction of the scoliotic deformity. H: Sagittal T2-weighted MR image obtained 4 years after the instrumented fusion demonstrating progression of the cervical kyphotic deformity.

pediatric patients with an IMSCT, including neurogenic (aka paralytic) deformity, postradiotherapy deformity, and postlaminectomy deformity. Neurogenic deformity with a number of conditions that produce neuromuscular denervation, including spinal cord injury, has been described..$^{17,21}$ Among patients with an IMSCT, anterior horn cell involvement by the tumor can lead to muscle denervation; loss of integrity of the paraspinal musculature in particular results in progressive deformity. ${ }^{31,37} \mathrm{~A}$ similar effect can be found in patients with expanding syringomyelia if damage occurs to the anterior horn cells. ${ }^{12,13}$ These changes in musculoskeletal loading typically account for the presence of preoperative spinal deformity in patients who have not yet undergone resection of the IMSCT. In the current series, of the 29 patients with available preoperative imaging, we found evidence of preoperative deformity in $8(28 \%)$ patients. In addition, irreversible neuromuscular denervation can cause persistent and/or progressive spinal deformity, even after IMSCT resection and surgical correction of the deformity. ${ }^{2}$

Radiation therapy is also an important risk factor for the development of pediatric spinal deformity, even in the absence of surgery. In our series, 7 (11\%) patients underwent radiation therapy before presenting to our institution, and $8(12 \%)$ patients were treated with radiation after their initial presentation and resection. Two patients who under- 
TABLE 3. Features of the 10 patients who required instrumented fusion

\begin{tabular}{lc}
\hline \multicolumn{1}{c}{ Variable } & No. $(\%)$ \\
\hline \multicolumn{2}{l}{ Instrumentation } \\
\hline Growing rods & $1(10)$ \\
\hline Posterior fusion & $8(80)$ \\
\hline Anterior and posterior fusion & $1(10)$ \\
\hline Location of IMSCT & $2(20)$ \\
\hline Cervical & $4(40)$ \\
\hline Thoracic & $3(30)$ \\
\hline Cervicothoracic & $3(30)$ \\
\hline Lumbar and/or sacral & $2(20)$ \\
\hline Previous radiotherapy & $5(3-6)$ \\
\hline Median no. of levels (IQR) & $31.9(14.6-50.3)$ \\
\hline Median interval between earliest resection \\
and fusion in mos (IQR)
\end{tabular}

went radiation therapy ultimately required surgical fusion. Spinal deformity after radiotherapy was described as early as $1950 .{ }^{5}$ Radiation damages the growth plates of the vertebral bodies, which produces irregular endplates and loss of vertebral body height. Asymmetrical involvement of the vertebral body can result in anterior or lateral wedging. Radiation therapy can produce spinal deformity in a delayed manner, and in particular can manifest during periods of rapid growth during puberty. In a retrospective study of 76 patients who underwent laminectomy or laminoplasty with or without adjuvant radiation therapy, postlaminectomy deformities were identified only 5-15 months after surgery, whereas radiation-induced deformities did not appear until 77 months after the treatment was completed. ${ }^{8}$

In addition to neurogenic deformity and radiationinduced deformity, postlaminectomy kyphosis has commonly been described among patients undergoing resection of an IMSCT. Biomechanical studies have found that under normal conditions when cervical lordosis exists, the weight-bearing axis of the spine is posterior to the vertebral bodies. However, the weight-bearing axis shifts anteriorly once the posterior elements are removed after cervical laminectomy, which results in a loss of lordosis and compression of the anterior elements of the spine while the posterior elements are placed under tension. However, pediatric patients with skeletally immature vertebral bodies are less able to maintain stable spinal alignment after surgical removal of the posterior tension band, which results in progressive kyphotic deformity. ${ }^{10,37}$ Iatrogenic biomechanical changes likely explain why many of the patients in the current series developed loss of cervical lordosis with progression to cervical kyphosis. Preservation of the extensor musculature of the spine and preservation of at least $50 \%$ of the facet capsule are both important measures for reducing the incidence of instability after laminectomy. ${ }^{25,38}$

Postlaminectomy deformity occurs more commonly in the pediatric population than in adults, ${ }^{19,24,36}$ which has been attributed to several features of the skeletally im- mature spine, including a higher proportion of cartilage, greater viscoelasticity and increased ligamentous laxity, and facet joints that are more horizontally oriented. ${ }^{8,10,35} \mathrm{In}$ addition, the younger the patient at the time of surgery, the longer the spine will continue to grow in a biomechanically altered setting. Therefore, Yao et al. ${ }^{35}$ identified age less than or equal to 13 years at the time of surgery as a significant predictor of progressive postoperative deformity.

The presence of a preoperative deformity has also been associated with a higher risk of progressive postoperative deformity. In a study of 161 consecutive pediatric patients with an IMSCT, 56 patients had a preoperative deformity, defined as a scoliotic deformity with a Cobb angle greater than $10^{\circ}{ }^{35}$ None of the patients had a preoperative kyphotic or lordotic deformity. Among these 56 patients, the deformity progressed in $26(46 \%)$ patients, remained stable in $24(43 \%)$ patients, and resolved in $6(11 \%)$ patients. In addition to those patients with preoperative deformity who ultimately required fusion, 17 patients without preoperative deformity developed a new postoperative deformity and required subsequent fusion. A multivariate analysis revealed that the presence of preoperative deformity increased the risk of a subsequent spinal deformity requiring fusion by approximately 3 -fold. In another study of 55 patients who underwent laminectomy or laminoplasty for an IMSCT, 11 (20\%) patients had a preoperative deformity, 7 of whom later required surgical fusion for deformity. ${ }^{2}$ An additional 4 patients without a preoperative deformity developed kyphoscoliosis at a mean of 26 months after surgery. A multivariate analysis indicated that preoperative kyphoscoliosis was an independent predictor of developing spinal deformity that requires surgical fusion. In our series, of the 29 patients with available preoperative imaging, we found evidence of preoperative deformity in 8,4 of whom ultimately required surgical fusion.

Several other variables have been identified as predictors of progressive postoperative spinal deformity after IMSCT resection. Several authors reported that the number of levels removed during laminectomy plays an important role. Sciubba et al. ${ }^{31}$ found that $33 \%$ of their patients who underwent laminectomy that involved 3 or more levels developed cervical instability and eventually required fusion, compared with 5\% of the patients who underwent a 2-level laminectomy $(\mathrm{p}=0.03)$. Similarly, Katsumi et al. ${ }^{16}$ found that $46 \%$ of their patients who underwent laminectomy that involved 4 or more levels developed postlaminectomy kyphosis, which occurred 4 times more frequently than in patients who underwent removal of 3 levels or less. Other predictors of progressive postoperative deformity requiring fusion include involvement of the thoracolumbar junction, the presence of a tumor-associated syrinx, resection of the tumor more than 1 month after the onset of symptoms, and the need for multiple IMSCT resections. ${ }^{35}$

Given the association between laminectomy and progressive postoperative spinal deformity, laminoplasty has been advocated as an alternative technique designed to reduce the incidence of deformity. ${ }^{1,22,27}$ Laminoplasty partially restores the posterior tension band and secures the resected laminae to the remaining posterior spinal elements, which theoretically minimizes biomechanical disruption 
after the resection of an IMSCT. Results have been mixed. In a retrospective study of 18 patients who underwent laminectomy and 9 patients who underwent laminoplasty for an IMSCT, laminoplasty decreased the incidence of postoperative deformity and fusion in patients whose tumor was in the thoracic or thoracolumbar region. ${ }^{37}$ Similarly, in a cohort of 141 patients who underwent laminectomy and 20 patients who underwent laminoplasty, McGirt et al. ${ }^{22}$ found that laminoplasty was associated with a 7-fold decrease in the incidence of fusion for progressive deformity. In contrast, a meta-analysis performed in 2003 identified high rates of deformity in patients who had undergone laminoplasty and did not find a significant difference in fusion rates between patients who had undergone laminectomy and those who had undergone laminoplasty. ${ }^{28} \mathrm{~A}$ more recent study found that postoperative deformity was present in 4 of 5 patients who underwent laminoplasty for IMSCT resection. ${ }^{4}$

In our series, patients who underwent laminectomy and those who underwent laminoplasty had similar baseline characteristics, with the exception that patients in the laminectomy cohort were more likely to have had previous treatment before presenting to our institution. As a result, patients who underwent laminectomy were more likely to have had more than 1 surgery. It should be noted that undergoing laminoplasty did not reduce the incidence of subsequent fusion in our patients. Instrumented fusion was performed in $11 \%$ of the laminectomy cohort and $17 \%$ of the laminoplasty cohort. Despite the care that is taken to avoid disruption of the facet joints during laminoplasty, and the theoretical restoration of the posterior tension band during this procedure, a degree of biomechanical instability is likely caused by muscle dissection and the resulting postoperative muscle atrophy. Similar findings were seen in a series of 43 patients who underwent laminectomy and 12 who underwent laminoplasty over a mean followup period of 11.4 years; surgical fusion was necessary in $21 \%$ of the patients who underwent laminectomy and in $17 \%$ of those who underwent laminoplasty $(p=0.7179){ }^{2}$ The authors suggested that although laminoplasty might not eliminate the long-term risk of developing deformity, it might promote wound healing, reduce the incidence of CSF leaks, and establish a safer plane for surgical dissection during repeat resections.

An alternative strategy for reducing the risk of progressive postoperative deformity involves performing early or even concurrent fusion in children with an IMSCT. In a series of 52 children with an IMSCT, 32 underwent laminectomy, 5 underwent laminoplasty, 8 underwent decompression and in situ fusion, and 7 underwent decompression with instrumented spinal fusion. ${ }^{4}$ The authors found that $57 \%$ of the patients without concurrent fusion developed moderate or severe postoperative deformity, whereas only $27 \%$ of the patients who underwent spinal fusion did so. The effect of concurrent fusion became even more apparent when the authors excluded patients with tumor progression that had caused progressive motor deficits. They noted that neurogenic/paralytic deformity is not necessarily prevented by concurrent fusion, whereas postlaminectomy kyphosis might indeed be prevented by the patient undergoing fusion prophylactically. It should be noted that posterior fusion might be associated with a high rate of pseudarthrosis and adjacent-segment disease. Furthermore, posterior fusion can produce a "crank-shaft" deformity in children as a result of persistent growth of the anterior column of the spine..$^{18,29}$ In our series, we found that 4 of the 10 patients who underwent fusion required more than 1 procedure as a result of adjacent-segment disease. In addition, early or concurrent fusion might result in hardware-induced artifacts on MRI and potentially interfere with subsequent monitoring for tumor recurrence on imaging. Indeed, the IMSCT in 3 of the 10 patients in our cohort who underwent instrumented fusion ultimately recurred and required a re-resection subsequent to the primary fusion, which highlights the importance of highquality surveillance imaging. As a result, it has been our practice to avoid concurrent fusion. Rather, we favor close surveillance of patients who are felt to be at high risk of developing deformity. Decision making regarding the timing of instrumented fusion is made in collaboration with a pediatric spinal deformity specialist, and such decisions typically are triggered by significant progression of the patient's deformity despite nonsurgical treatment (such as bracing).

This study had several limitations. In addition to the inherent limitations of a retrospective study, all of the patients in this cohort underwent surgery with the same surgeon, which thereby limits the generalizability of the results. In addition, we found that a substantial proportion of the patients in our series were referred from other institutions. In fact, 27 of the 66 patients had already undergone either a biopsy or resection of their IMSCT before arriving at our institution for further management. As a result, our access to these patients' preoperative imaging was limited, and our ability to determine the presence of deformity before their first surgery was hindered. In addition, after their initial recovery period, many of these patients had limited follow-up time because of travel restrictions, which resulted in a lower duration of follow-up for some of them. Longer follow-up might have identified additional patients who required spinal fusion in a delayed fashion. Furthermore, the presence or absence of spinal deformity before and after surgery was often determined based on interval MRI scans, because standing scoliosis radiographs were not routinely obtained until the deformity became clinically evident. To counter these limitations, future studies should prospectively collect complete imaging records from patients so that their radiological status can be monitored closely over time.

\section{Conclusions}

Progressive spinal deformity in pediatric patients undergoing IMSCT treatment might result from a combination of neurogenic/paralytic deformity, radiation-induced deformity, and/or postlaminectomy kyphosis. Laminoplasty, in particular, is being used by some surgeons to reduce the incidence of postoperative deformity after IMSCT resection. Nevertheless, we found that in our series of patients, which to our knowledge is the largest cohort of pediatric patients to have undergone laminoplasty for IMSCT resection, fusion rates remained high. Known risk 
factors, such as the age of the patient, location of the tumor, and the number of levels involved, might play a larger role than replacement of the laminae in determining the rate of surgical fusion after IMSCT resection. Laminoplasty might confer other benefits, including establishment of a safer plane for surgical dissection during re-exploration. Nevertheless, our findings suggest that after laminoplasty for IMSCT resection, pediatric patients should continue to undergo close surveillance for progressive spinal deformity.

\section{References}

1. Abbott R, Feldstein N, Wisoff JH, Epstein FJ: Osteoplastic laminotomy in children. Pediatr Neurosurg 18:153-156, 1992

2. Ahmed R, Menezes AH, Awe OO, Mahaney KB, Torner JC, Weinstein SL: Long-term incidence and risk factors for development of spinal deformity following resection of pediatric intramedullary spinal cord tumors. J Neurosurg Pediatr 13:613-621, 2014

3. Albert TJ, Vacarro A: Postlaminectomy kyphosis. Spine (Phila Pa 1976) 23:2738-2745, 1998

4. Anakwenze OA, Auerbach JD, Buck DW, Garg S, Simon SL, Sutton LN, et al: The role of concurrent fusion to prevent spinal deformity after intramedullary spinal cord tumor excision in children. J Pediatr Orthop 31:475-479, 2011

5. Arkin AM, Simon N: Radiation scoliosis; an experimental study. J Bone Joint Surg Am 32A:396-401, 1950

6. Cattell HS, Clark GL Jr: Cervical kyphosis and instability following multiple laminectomies in children. J Bone Joint Surg Am 49:713-720, 1967

7. Constantini S, Miller DC, Allen JC, Rorke LB, Freed D, Epstein FJ: Radical excision of intramedullary spinal cord tumors: surgical morbidity and long-term follow-up evaluation in 164 children and young adults. J Neurosurg 93 (2 Suppl):183-193, 2000

8. de Jonge T, Slullitel H, Dubousset J, Miladi L, Wicart P, Illés T: Late-onset spinal deformities in children treated by laminectomy and radiation therapy for malignant tumours. Eur Spine J 14:765-771, 2005

9. Evans AE, Norkool P, Evans I, Breslow N, D’Angio GJ: Late effects of treatment for Wilms' tumor. A report from the National Wilms' Tumor Study Group. Cancer 67:331-336, 1991

10. Fassett DR, Clark R, Brockmeyer DL, Schmidt MH: Cervical spine deformity associated with resection of spinal cord tumors. Neurosurg Focus 20(2):E2, 2006

11. Fraser RD, Paterson DC, Simpson DA: Orthopaedic aspects of spinal tumors in children. J Bone Joint Surg Br 59:143151,1977

12. Huebert HT, MacKinnon WB: Syringomyelia and scoliosis. J Bone Joint Surg Br 51:338-343, 1969

13. Isu T, Chono Y, Iwasaki Y, Koyanagi I, Akino M, Abe H, et al: Scoliosis associated with syringomyelia presenting in children. Childs Nerv Syst 8:97-100, 1992

14. Jallo GI, Freed D, Epstein F: Intramedullary spinal cord tumors in children. Childs Nerv Syst 19:641-649, 2003

15. Jallo GI, Kothbauer KF, Epstein FJ: Intrinsic spinal cord tumor resection. Neurosurgery 49:1124-1128, 2001

16. Katsumi Y, Honma T, Nakamura T: Analysis of cervical instability resulting from laminectomies for removal of spinal cord tumor. Spine (Phila Pa 1976) 14:1171-1176, 1989

17. Lancourt JE, Dickson JH, Carter RE: Paralytic spinal deformity following traumatic spinal-cord injury in children and adolescents. J Bone Joint Surg Am 63:47-53, 1981

18. Lee CS, Nachemson AL: The crankshaft phenomenon after posterior Harrington fusion in skeletally immature patients with thoracic or thoracolumbar idiopathic scoliosis followed to maturity. Spine (Phila Pa 1976) 22:58-67, 1997

19. Lonstein JE: Post-laminectomy kyphosis. Clin Orthop Relat Res (128):93-100, 1977

20. Lord CF, Herndon JH: Spinal cord compression secondary to kyphosis associated with radiation therapy for metastatic disease. Clin Orthop Relat Res (210):120-127, 1986

21. Mayfield JK, Erkkila JC, Winter RB: Spine deformity subsequent to acquired childhood spinal cord injury. J Bone Joint Surg Am 63:1401-1411, 1981

22. McGirt MJ, Chaichana KL, Atiba A, Bydon A, Witham TF, Yao KC, et al: Incidence of spinal deformity after resection of intramedullary spinal cord tumors in children who underwent laminectomy compared with laminoplasty. J Neurosurg Pediatr 1:57-62, 2008

23. McGirt MJ, Constantini S, Jallo GI: Correlation of a preoperative grading scale with progressive spinal deformity following surgery for intramedullary spinal cord tumors in children. J Neurosurg Pediatr 2:277-281, 2008

24. Mikawa Y, Shikata J, Yamamuro T: Spinal deformity and instability after multilevel cervical laminectomy. Spine (Phila Pa 1976) 12:6-11, 1987

25. Nolan JP Jr, Sherk HH: Biomechanical evaluation of the extensor musculature of the cervical spine. Spine (Phila Pa 1976) 13:9-11, 1988

26. Papagelopoulos PJ, Peterson HA, Ebersold MJ, Emmanuel PR, Choudhury SN, Quast LM: Spinal column deformity and instability after lumbar or thoracolumbar laminectomy for intraspinal tumors in children and young adults. Spine (Phila Pa 1976) 22:442-451, 1997

27. Raimondi AJ, Gutierrez FA, Di Rocco C: Laminotomy and total reconstruction of the posterior spinal arch for spinal canal surgery in childhood. J Neurosurg 45:555-560, 1976

28. Ratliff JK, Cooper PR: Cervical laminoplasty: a critical review. J Neurosurg 98 (3 Suppl):230-238, 2003

29. Rauzzino MJ, Shaffrey CI, Wagner J, Nockels R, Abel M: Surgical approaches for the management of idiopathic thoracic scoliosis and the indications for combined anteriorposterior technique. Neurosurg Focus 6(5):e6, 1999

30. Reimer R, Onofrio BM: Astrocytomas of the spinal cord in children and adolescents. J Neurosurg 63:669-675, 1985

31. Sciubba DM, Chaichana KL, Woodworth GF, McGirt MJ, Gokaslan ZL, Jallo GI: Factors associated with cervical instability requiring fusion after cervical laminectomy for intradural tumor resection. J Neurosurg Spine 8:413-419, 2008

32. Simon SL, Auerbach JD, Garg S, Sutton LN, Telfeian AE, Dormans JP: Efficacy of spinal instrumentation and fusion in the prevention of postlaminectomy spinal deformity in children with intramedullary spinal cord tumors. J Pediatr Orthop 28:244-249, 2008

33. Steinbok P, Cochrane DD, Poskitt K: Intramedullary spinal cord tumors in children. Neurosurg Clin N Am 3:931-945, 1992

34. Tachdjian MO, Matson DD: Orthopaedic aspects of intraspinal tumors in infants and children. J Bone Joint Surg Am 47:223-248, 1965

35. Yao KC, McGirt MJ, Chaichana KL, Constantini S, Jallo GI: Risk factors for progressive spinal deformity following resection of intramedullary spinal cord tumors in children: an analysis of 161 consecutive cases. J Neurosurg 107 (6 Suppl):463-468, 2007

36. Yasuoka S, Peterson HA, MacCarty CS: Incidence of spinal column deformity after multilevel laminectomy in children and adults. J Neurosurg 57:441-445, 1982

37. Yeh JS, Sgouros S, Walsh AR, Hockley AD: Spinal sagittal malalignment following surgery for primary intramedullary tumours in children. Pediatr Neurosurg 35:318-324, 2001

38. Zdeblick TA, Zou D, Warden KE, McCabe R, Kunz D, 
Vanderby R: Cervical stability after foraminotomy. A biomechanical in vitro analysis. J Bone Joint Surg Am 74:22-27, 1992

\section{Disclosures}

The authors report no conflict of interest concerning the materials or methods used in this study or the findings specified in this paper.

\section{Author Contributions}

Conception and design: Groves, Jallo. Acquisition of data: Hersh, Iyer, Garzon-Muvdi, Liu. Analysis and interpretation of data: Groves, Hersh, Iyer, Jallo. Drafting the article: Hersh. Critically revising the article: all authors. Reviewed submitted version of manuscript: all authors. Approved the final version of the manu- script on behalf of all authors: Groves. Statistical analysis: Hersh. Study supervision: Groves, Jallo.

\section{Supplemental Information}

Previous Presentations

Some of the patients included in this work were included in unrelated abstracts that were presented at the following: 2014 Annual Meeting of the American Association of Neurological Surgeons/ Congress of Neurological Surgeons Section on Pediatric Neurological Surgery, Amelia Island, Florida, December 2-5, 2014, and the 2015 CNS Annual Meeting New Orleans, Louisiana, September 26-30, 2015.

\section{Correspondence}

Mari L. Groves, Johns Hopkins Hospital, 600 N Wolfe St., Phipps 556, Baltimore, MD 21287. email: mgroves2@jhmi.edu. 